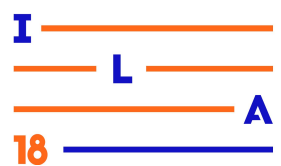

\title{
AMAZON ECHO DOT - PROPOSTA DE APLICAÇÃO DO ANTICIPATORY DESIGN A INTERFACE CONVERSACIONAL
}

\section{AMAZON ECHO DOT - ANTICIPATORY DESIGN APPLICATION PROPOSAL TO CONVERSATIONAL INTERFACE}

\author{
Edson Luiz', Esp. \\ Eduardo Oliveira ${ }^{2}$, M.Sc. \\ (1) Faculdade dos Guararapes \\ e-mail: edson.mobile@gmail.com \\ (2) Centro de Estudos e Sistemas Avançados do Recife - C.E.S.A.R \\ e-mail: ejgo@cesar.org.br
}

Palavras chaves: Anticipatory design, Interface conversacional, IoT

Este artigo pretende propor a aplicação do Anticipatory Design a interface conversacional do Amazon Echo Dot, através de um teste comparativo, aplicando o SUS (System Usability Scale). Com o objetivo de descobrir qual das versões obteve maior aceitação dos participantes segundo o resultado do SUS.

Key-words: Anticipatory design, Conversacional interface, IoT

This article intends to propose the application of Anticipatory Design to Amazon Echo Dot conversational interface through a comparative test, applying the System Usability Scale (SUS). The objective is what version was more accepted following the SUS result.

\section{Introdução}

Com o passar dos anos e o avanço tecnológico, nós seres humanos, estamos cada vez mais dependentes da tecnologia, dependência esta que reflete o nosso dia a dia na forma que interagimos com esses artefatos. Principalmente os artefatos com base tecnológica que auxiliam os usuários a se comunicar, se informar e se locomover. Dentre estes, podemos destacar os objetos conectados ou mais conhecidos como IoT(Internet of Things) que se conectam a internet e utilizam sensores eletrônicos para coletar dados e para conexão com equipamentos similares.

Este presente trabalho tem como objetivo apresentar o Anticipatory Design e como esta metodologia poderá colaborar para a evolução dos equipamentos conectados, ampliando sua interação com os usuários e auxiliando tomadas de decisão no seu dia a dia.

O objeto de estudo deste trabalho foi o assistente pessoal Amazon Echo Dot. Este equipamento auxilia o usuário a efetuar pequenas atividades através da interação por voz. Visando promover a aplicabilidade do Anticipatory Design a interface conversacional da Amazon, efetuando testes comparativos entre a versão existente no mercado com a proposta deste experimento.

\subsection{Objetivo}

Este artigo tem como objetivo, promover a aplicabilidade do Anticipatory Design a interface conversacional do Amazon Echo Dot. Que, por meio de um teste comparativo e um questionário aplicado ao final, visa analisar quais das propostas teve maior aceitação e se a sua aplicabilidade auxilia de forma efetiva nas tomadas de decisão dos usuários. Após a consolidação dos resultados, este artigo espera servir de base para projetos futuros.

\subsection{Justificativa}

O que impulsionou a realização deste trabalho foi a 


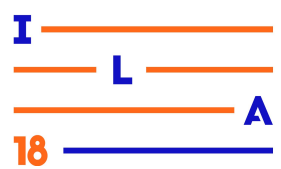

popularização das interfaces conversacionais no dia a dia das pessoas e propor uma melhoria na forma de interação do assistente virtual Amazon Echo Dot através de uma análise comparativa, visando a melhoria da experiência dos seus usuários com base em conceitos de design de interação e princípios do Anticipatory Design.

\subsection{Estrutura do artigo}

Nas próximas páginas estão presentes, pesquisas e estudos de alguns autores focados em Anticipatory Design e Interfaces Conversacionais, com o objetivo de esclarecer e embasar a proposta deste artigo.

Foi realizado um teste comparativo com 5 usuários utilizando duas versões. Uma versão simulando o comportamento do assistente virtual Amazon Echo Dot que está no mercado atualmente e uma outra versão simulando a aplicação da proposta referente a este artigo. Servindo como base para trabalhos futuros de design de interação e interfaces conversacionais.

\section{Revisão do estado da arte}

\subsection{Anticipatory Design}

De acordo com Van Bodegraven (2018), (em tradução livre) o Anticipatory Design é um conceito bastante novo dentro da comunidade de design, e a ideia foi cunhada pela primeira por Aaron Shapiro em 2016.

O Anticipatory Design é um princípio que move em torno de três conceitos: aprender, prever e antecipar. Este princípio já está implementado em vários produtos de uso comum, sem que estejamos ativamente conscientes disso. Produtos como o Nest, Netflix e Amazon Echo são bons exemplos de como um produto aprende, ajusta e antecipa dados e sugestões para os usuário.

Um bom exemplo da aplicação do Anticipatory Design é o Netflix que sugere aos usuários quais filmes assistir, baseado em suas escolhas e preferências. Levando em consideração, dados do histórico de uso e avaliações.

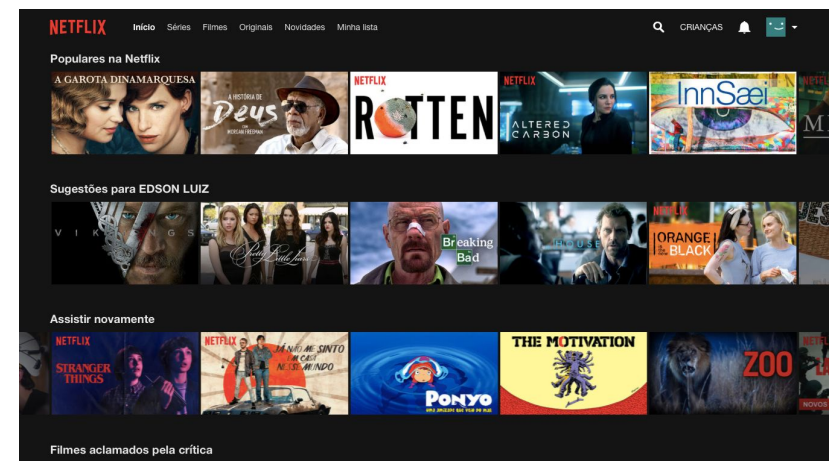

Figura 1 Tela inicial do Netflix Web. Acessado em: $14 / 04 / 2018$

Outro exemplo, é o Uber, onde ao finalizar uma viagem através do aplicativo, é fornecido para o usuário o botão "Retorno", pois, através de estudos, a companhia identificou que existe $90 \%$ de chance de seus usuários retornarem ao seu local de partida.

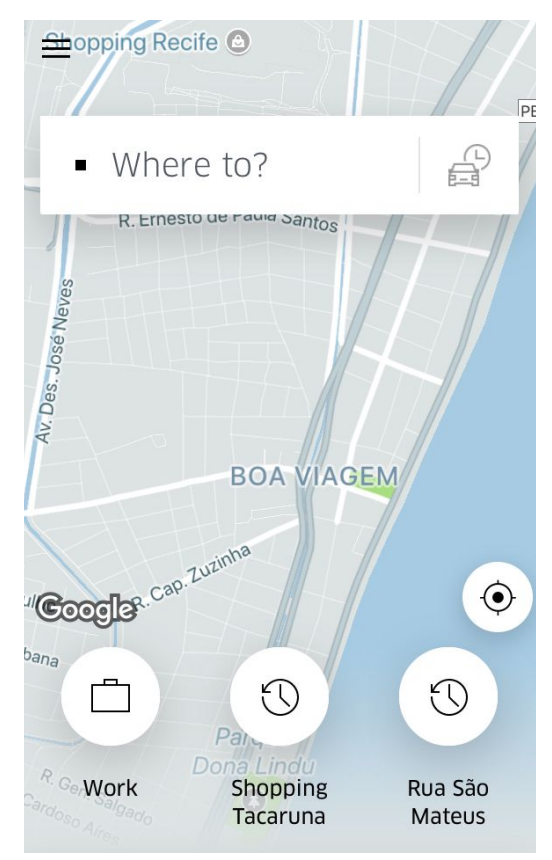

Figura 2 Tela inicial do aplicativo iOS do Uber. Acessado em: 14/04/2018

Os exemplos citados acima, são aplicações dos princípios de Anticipatory Design, que para funcionar de forma efetiva, segue três características básicas de diferentes disciplinas:

- Aprender - IoT(Internet das coisas)

- Prever- Machine Learning 


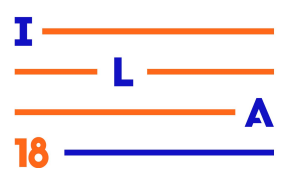

- Antecipar - UX Design

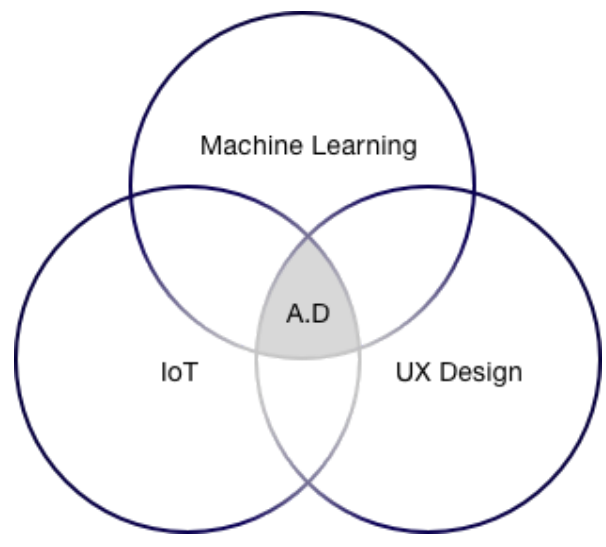

Figura 3 Van Bodegraven, Joë (2018)

Dessa maneira o UX Design tem o papel fundamental de proporcionar uma boa experiência, utilizando o Machine learning para observar e o IoT para aprender a rotina dos usuários. Que juntos interpretam esses dados e fornecem esta interação de forma antecipada.

É notável que a cada dia vem surgindo novos produtos ou serviços baseados em inovação tecnológica. Tornando nossa vida mais simples e automatizada até certo ponto, nos auxiliando a pedir uma refeição ou solicitar uma carona. Desta forma, somos abastecidos de informações que consequentemente nos colocam em situações de que é preciso tomar algumas decisões. Segundo Hoomans (2015), decisões essa, que pode chegar a aproximadamente $35.000 \mathrm{em}$ um período de 24 horas. Assim, com o passar do dia, às tomadas de decisões vão se tornando menos efetiva. Claro que esta quantidade varia com base nas atividades, experiências e desenvolvimento cerebral de cada indivíduo. A propósito, segundo Tierney (2011), existe uma alta probabilidade de um preso ter seu pedido de condicional deferido no início do dia. Isso acontece porque o Juiz está $30 \%$ mais apto a tomar decisões no início, do que ao final do dia.

Possivelmente, com o auxílio do Anticipatory Design, as pessoas não irão se preocupar em decidir qual será o seu próximo investimento, qual será o dia ideal para fazer a faxina e qual será a melhor rota seguir para o trabalho. Pois o seu veículo autônomo já terá decidido qual melhor caminho seguir.
Mas, para que chegamos a este nível, será preciso passar por uma evolução em vários estágios, onde no primeiro, algumas aplicações farão escolhas simples para os usuários, tais como pequenos algoritmos de sugestões, opções pré-selecionadas por padrão ou lembrar de suas preferências. No segundo estágio, os usuários terão a experiência de receber produtos ou serviços que passaram por uma curadoria, otimizados através das escolhas mais comuns, eliminando outras opções. E no último estágio, as escolhas serão antecipadas sem intervenção humana.

Por fim, existem alguns riscos que devem ser levados em consideração durante este processo de evolução, um deles, e não menos importante, é o comportamento dos dispositivos que farão parte desta conexão em rede, pois alguns deles podem se comportar como se estivessem em uma bolha de experiência, ficando presos em um loop de eventos, trazendo grandes consequências na experiência dos usuários e nas escolhas que eles seguirão.

Dentro desta perspectiva, podemos fazer um paralelo com a afirmação de Pariser (2016), de que a personalização dos conteúdos na internet através das preferências dos usuários, está fazendo que eles vivam em bolhas de informação.

\subsection{Experiência do usuário}

Com a tecnologia cada vez mais presente na vida das pessoas, viu-se a necessidade dos usuários em querer cada vez mais gerenciar seus dispositivos e softwares que faziam parte do seu dia a dia. A partir disso, foi preciso definir alguns parâmetros para tornar a engenharia de software mais eficaz.

Tornando as necessidades do usuário como o centro de toda a cadeia de desenvolvimento. Possibilitando a criação de softwares mais específicos para um determinado público, levando em consideração os objetivos, experiências, necessidades e desejos dos usuários.

De acordo com a ISO 9241-11:210, a Experiência do Usuário inclui todas as emoções, crenças, preferências, percepções, respostas físicas e psicológicas, comportamentos e realizações do usuário resultante do uso de um produto, sistema ou serviço. 


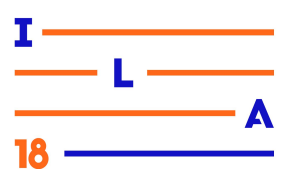

Por se tratar de um termo subjetivo, a Experiência do Usuário é difícil dizer que um designer pode projetar a Experiência do Usuário, mas podemos dizer que é possível projetar algo, seja um produto ou serviço para um determinado público alvo, proporcionando uma experiência satisfatória.

Donald Norman (2011) cunhou o termo UX (User Experience) para descrever melhor o que fazia no seu dia a dia, pois acreditava que seu trabalho ia muito além do escritório. Sobre o significado do termo, Norman disse o seguinte:

"Uma vez, há muito tempo atrás, eu estava na Apple e estávamos conversando como a experiência de usar esses computadores era ruim:

A experiência da descoberta, quando você vê ele pela primeira vez em uma loja, quando você compra ele, quando não consegue colocá-lo no carro porque a caixa é muito grande e não cabe dentro do carro e quando finalmente chega em casa, abre a caixa e diz:

"Ooh....parece assustador. Eu não me atreveria a montar esse computador"

Tudo isso é experiência do usuário. Tudo relacionado a sua experiência com o produto. Talvez nem precise estar perto do produto ou talvez quando você está conversando com alguém sobre ele. É isso o que queríamos dizer quando inventamos o termo "Experiência do Usuário"."

A Experiência do Usuário está presente em produtos do nosso dia a dia, seja um objeto utilitário, móvel, página web ou um aplicativo para smartphone. Norman (2008) afirma que essa experiência pode ser manifestada em três diferentes níveis de processamento emocional: Visceral, Comportamental ou Reflexivo.

- Nível visceral: É o nível em que o usuário responde de forma mais imediata ao ter contato com o artefato. Representado por julgamentos espontâneos em relação aos aspectos visuais e outros níveis sensoriais. Muitos de nós já tivemos a experiência de ter contato com algum produto e antes mesmo de saber quanto custa, já estamos encantado por ele.

- Nível comportamental: Este nível é relacionado a experiência do usuário em relação ao artefato. Representa o uso e desempenho objetivo das funções, como o usuário compreende e opera este artefato e consequentemente como o mesmo se comporta. Usuários que tiverem uma experiência frustrada ou confusa, podem atingir um estado negativo.

- Nível reflexivo: Este nível está relacionado a impressões e reflexões relacionadas a experiências passadas relacionadas ao artefato.

\subsection{Interface Conversacional}

Como descrito por Teixeira (2016), uma interface conversacional é aquela que acontece em forma de conversa entre o humano e uma máquina. Há quem argumente dizendo que toda interface é na verdade, uma conversa. Mas nesse caso a interface também tem a aparência de uma conversa, como se estivesse utilizando algum aplicativo de chat.

A grande vantagem desse tipo de interface é a naturalidade da interação: quando bem desenhada parece que o usuário está realmente conversando com a máquina. Em alguns casos a conversa acontece oralmente, através de voz. (Teixeira, 2016)

Os chatbots também são considerados interface conversacional, baseados em A.I. Respondem coisas simples para os usuários dependendo do seu contexto, interagindo através de texto. Por outro lado, os assistentes virtuais como o Alexa. Funcionam por meio de comandos por voz, transmitindo para o usuário apenas o que lhe foi perguntado.

Dessa forma, podemos dizer que através da interface conversacional o usuário interage por digitação e voz.

\subsection{Internet das coisas (IoT)}

No início dos anos 2000, Kevin Ashton estabeleceu a base para o que seria a Internet das Coisas (IoT) em um laboratório de AutoID no MIT

(Massachusetts Institute of Technology). Ashton foi um dos pioneiros que criou essa noção enquanto pesquisava maneiras de a Procter \& Gamble 


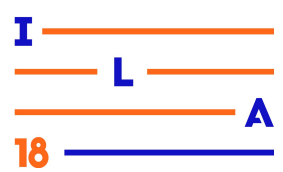

melhorar suas transações comerciais conectando informações RFID à Internet. O conceito era simples, porém eficiente. Se todos os objetos do dia a dia fossem equipados com identificadores e conectividade sem fio, eles poderiam se comunicar e gerenciados por computadores. (Lopez Research, 2013)

Em Ashton (2009) vamos encontrar o seguinte esclarecimento (em tradução livre):

"Se tivéssemos computadores que soubessem tudo sobre as coisas em geral -- usando dados coletados sem a nossa ajuda -- seríamos capazes de rastrear, e reduzir bastante o desperdício, a perda e os custos. Nós saberíamos quando é necessário substituir, reparar ou fazer um recall de um produto, e se estão novos ou ultrapassados. Precisamos capacitar os computadores com seus próprios meios de coletar informações para que possam ver, ouvir e cheirar o mundo sozinhos. O RFID e a tecnologia de sensores capacitam os computadores a observar, identificar e entender o mundo sem as limitações dos dados inseridos pelos humanos."

A Internet das Coisas pode ser considerada qualquer objeto físico que possui uma camada digital que esteja de alguma forma conectado em rede. Segundo Meira (2017), existe um conjunto de características desejáveis para que esse objeto opere:

1. Cada e toda coisa está [mas não necessariamente de forma permanente] na rede;

2. A forma de uma coisa se conectar à rede é [quase sempre] wireless;

3. A vasta maioria das coisas é múltipla [pode haver uma infinidade de cópias] mas...

4. Cada coisa é identificável de forma única [ou seja, pode ser endereçada] e...

5. Coisas obedecem ao princípio SFO [search, find, obtain; ou seja, dá pra procurar, encontrar e obter uma cópia de uma coisa, se existir]; mas...

6. As características de computação, comunicação e controle de tais coisas são [quase sempre] imperceptíveis [a "olho nu"] porque...

7. As coisas estão embarcadas, embutidas, associadas ou, de resto, fazem parte de objetos físicos e, também por causa disso,...

8. As coisas têm interface [quase sempre] "invisível". Ainda mais, coisas...

9. Carregam seu próprio plano de construção, uso e reciclagem e, por fim...

10. Uma coisa guarda ou deposita na rede seu rastro histórico.

A tabela abaixo, cita alguns meios de interações com as interfaces IoT e quais são os dispositivos que a utilizam. Para este presente trabalho, podemos destacar entre elas a interface por voz.

\begin{tabular}{|l|l|}
\hline Métodos de Input & Usados em: \\
\hline Touch, Click & $\begin{array}{l}\text { Controles físicos, } \\
\text { Touchscreens }\end{array}$ \\
\hline Movimento e manipulação & Interfaces tangíveis \\
\hline Voz & Reconhecimento por voz \\
\hline Corporal & $\begin{array}{l}\text { Reconhecimento por gestos, } \\
\text { Sensores de proximidades }\end{array}$ \\
\hline Resposta Galvânica da pele & Detecção de stress \\
\hline Pensamentos & $\begin{array}{l}\text { Interfaces de computação } \\
\text { cerebral }\end{array}$ \\
\hline Batimento cardíaco & $\begin{array}{l}\text { Detectar ansiedade, sono e } \\
\text { stress }\end{array}$ \\
\hline
\end{tabular}

Tabela 1 Formas de interação IoT. Adaptado de Rowland (2015)

Segundo Rowland (2015), às interfaces de voz são uma maneira poderosa de inserir ou gerar informações razoavelmente complexas.

Possibilitando aos usuários operá-las enquanto fazem outras coisas. No entanto, eles são lineares e o sistema apresenta ao usuário uma opção por vez. Para uma entrada eficiente, o usuário precisa lembrar quais tipos de comandos o sistema pode entender.

Por exemplo, os aplicativos para dispositivos móveis como o Siri, Google Now e Cortana combinam informações visuais e auditivas. Além dos dispositivos que interagem somente por voz, como o Amazon Echo Dot e o Google Home. Todos estes aplicativos e dispositivos fazem parte do que poderíamos chamar de segunda era da VUI (Voice User Interface). (PEARL, 2017) 


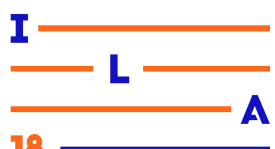

Para este experimento, foi utilizado o Amazon Echo Dot como objeto de estudo, através de uma avaliação descrita adiante. Este aparelho pertence a família Amazon Echo, que se conecta ao sistema da assistente virtual inteligente chamada de Alexa. Possibilitando os usuários interagirem por meio da voz, para executar funções como tocar músicas, criar listas de tarefas, configurar alarmes, além de informações sobre trânsito, temperatura, entre outras funcionalidades disponíveis.

\section{Metodología}

Este experimento teve caráter Hipotético-dedutivo. De acordo com Marconi e Lakatos (2003), realizam-se testes que consistem em tentativas de falseamento de eliminação e erros. Que consiste em falsear, isto é, em tornar falsas as conseqüências deduzidas ou deriváveis da hipótese.

Com o objetivo de validar a proposta do Anticipatory Design para o Amazon Echo Dot foi utilizada a técnica de teste $\mathrm{A} / \mathrm{B}$. A técnica consiste em gerar duas versões de um mesmo artefato, seja digital ou físico e liberar o uso de uma versão para uma base de usuário A e outra para uma base B. Assim, é possível analisar qual das duas versões obteve maior performance próximo ao objetivo do teste. (NIELSEN, 2015)

Antes de iniciar os testes, foi preciso executar algumas etapas:

- Roteiro: Serve para auxiliar o facilitador conduzir o teste com a proposta de ser direto e manter uma padronização entre todos os participantes, deixando-os mais à vontade durante o teste.

- Tarefas: São atividades repassadas pelo facilitador para os participantes executem durante o teste.

- Artefatos para o teste: Como mencionado anteriormente, para executar um teste $\mathrm{A} / \mathrm{B}$ é preciso duas propostas de um mesmo artefato. Estas propostas estão apresentadas na tabela abaixo.

\begin{tabular}{|l|l|}
\hline Proposta A & Proposta B \\
\hline Sem previsão de chuva para & Bom dia, previsão de chuva \\
\hline
\end{tabular}

\begin{tabular}{|c|c|}
\hline hoje & no início da tarde \\
\hline 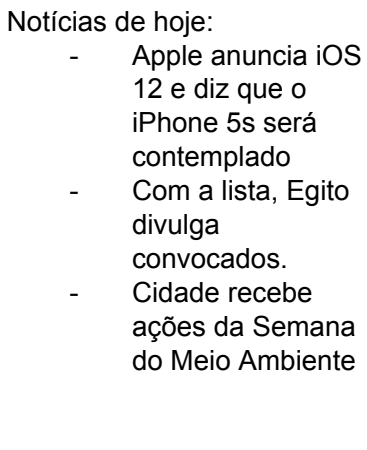 & $\begin{array}{l}\text { Bom Dia. Separamos as } \\
\text { melhores notícias de hoje } \\
\text { para você. } \\
\text { - } \quad \text { Apple anuncia iOs } \\
12 \text { e diz que o } \\
\text { iPhone } 5 \text { s será } \\
\text { contemplado } \\
\text { - } \quad \text { Com a lista, Egito } \\
\text { divulga } \\
\text { convocados. } \\
\text { - Cidade recebe } \\
\text { ações da Semana } \\
\text { do Meio Ambiente }\end{array}$ \\
\hline 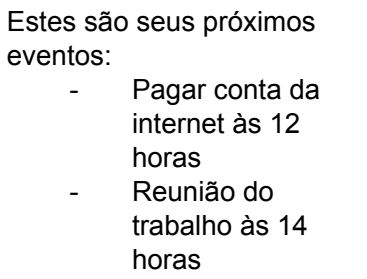 & $\begin{array}{l}\text { Bom dia, os seus eventos } \\
\text { para o dia de hoje são: } \\
\text { - } \quad \text { Pagar conta da } \\
\text { internet às } 12 \\
\text { horas } \\
\text { - } \quad \text { Reunião do } \\
\text { trabalho às } 14 \\
\text { horas }\end{array}$ \\
\hline
\end{tabular}

Tabela 2 versões dos artefatos criados para o teste

A tabela acima demonstra as duas versões dos áudios criados para o teste. Onde a Proposta A representava o comportamento do Amazon Echo Dot existente no mercado até o momento em que o experimento foi executado. A Proposta B representa uma versão com Anticipatory Design aplicado.

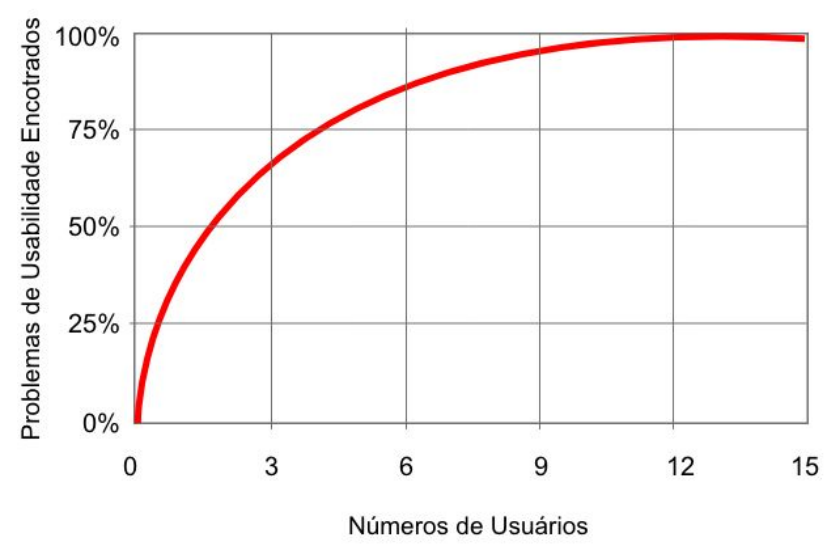

Figura 4 Fonte: Nielsen (2000)

Após estas etapas, foi preciso recrutar os participantes para o teste. Segundo Nielsen (2000), o ideal é que seja recrutados no mínimo cinco participantes para executar um teste de usabilidade. Pois como mostra na imagem acima, até cinco participantes é possível coletar até $80 \%$ de 


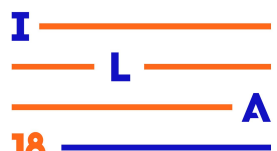

problemas de usabilidade.

Ao finalizar cada teste, seguindo a ordem, A-B. Foi aplicado um questionário SUS (System Usability Scale) para avaliar as duas versões de forma individual. O Método SUS foi criado por John Brooke (1986) para avaliar usabilidade de sistemas, porém ele pode ser utilizado para se averiguar o nível de usabilidade de produtos, serviços, hardware, software, aplicações e qualquer outro tipo de interface (Sauro, 2011).

De acordo com Brooke (1986), para calcular a pontuação do SUS é preciso primeiro somar as contribuições da pontuação de cada item. A contribuição da pontuação de cada item varia de 1 a 5. Para os itens 1,3,5,7 e 9, a contribuição da pontuação é a posição da escala menos 1 . Para os itens 2,4,6,8 e 10, a contribuição é de 5 menos a posição da balança. Multiplique a soma das pontuações por 2,5 para obter o valor global do SUS. Essa pontuação pode ir entre 0-100.

De acordo com Sauro (2011), uma pontuação do SUS acima de 68 pontos seria considerada acima da média e qualquer valor abaixo, estaria abaixo da média.

\section{Validação}

Para a realização dos testes, foram consideradas algumas características para o recrutamento dos participantes:

1. Os participantes deveriam ter tido algum contato prévio com assistente virtual físico ou embarcados nos sistemas $i O S$ e Android.

2. Os participantes deveriam ter o perfil de entusiastas a novas tecnologias, que gostam de comprar/experimentar produtos que ainda tenham pouca aderência no mercado apenas para testar ou ter a experiência de evolução do produto.

O testes foram realizados com 5 usuários, apresentado primeiro a versão A e em seguida a versão B. E ao finalizar responderam o SUS, alcançando o seguinte resultado:

\begin{tabular}{|c|c|c|c|c|}
\hline \multicolumn{5}{|c|}{ Proposta A } \\
\hline U1 & U2 & U3 & U4 & U5 \\
\hline 65.0 & 92.5 & 95.0 & 57.5 & 77.5 \\
\hline
\end{tabular}

Tabela 3. Resultados SUS da Proposta A

O usuário que avaliou a Proposta $\mathrm{A}$ com a menor pontuação, foi o U4. Definindo com a pontuação de 57.5 pontos, valor bem abaixo da média definida por Sauro (2011) que é de 68 ponto. Já o usuário U3, foi o que mais se adequou à Proposta A. Classificando com a pontuação de 95 pontos, bem próximo do valor máximo do SUS.

\begin{tabular}{|c|c|c|c|c|}
\hline \multicolumn{5}{|c|}{ Proposta B } \\
\hline U1 & U2 & U3 & U4 & U5 \\
\hline 77.5 & 92.5 & 100 & 82.5 & 85.0 \\
\hline
\end{tabular}

Tabela 4. Resultados SUS da Proposta B

Na Proposta B, nenhum dos participantes pontuou abaixo da média de 68 pontos. Podemos destacar na tabela o usuário U3, que classificou esta versão com a pontuação de 100 pontos, valor máximo do SUS

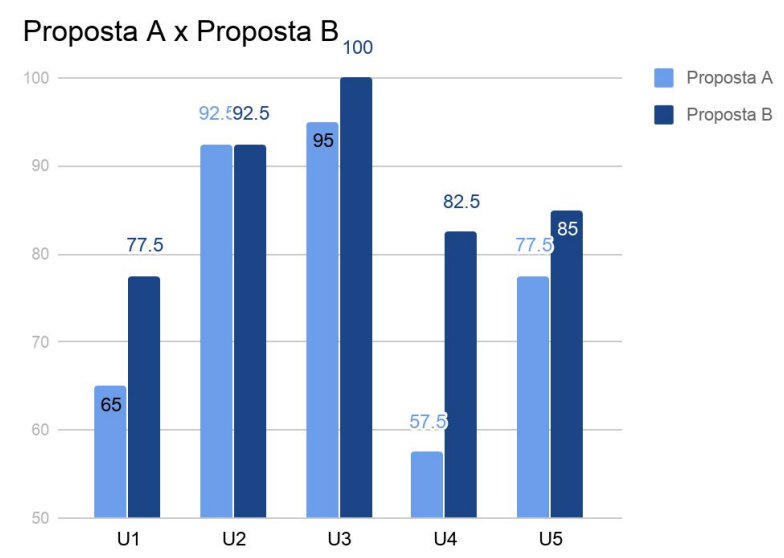

Gráfico 1. Comparativo do resultado das propostas

No gráfico comparativo entre as duas propostas, podemos destacar os seguintes resultados. O usuário U2 pontuou 92.5 para as duas versões. O usuário U3 pontuou 100 pontos para a Proposta B. Já o usuário U4, pontuou com o valor abaixo da média do SUS para a Proposta A e seu score para a Proposta B, obteve um crescimento significativo chegando a ter 25 pontos de diferença. 


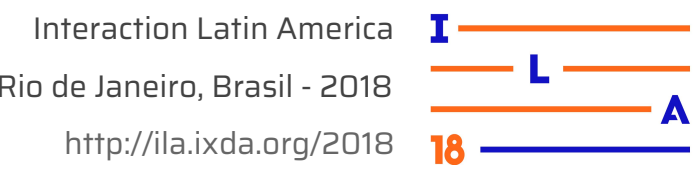

\section{Discussão}

Durante os testes, os usuários relataram muitos pontos positivos. Um deles foram os princípios de humanização seguidos para a criação dos artefatos da proposta deste experimento, podendo ser consultado na coluna da Proposta B na Tabela 2-Artefatos para o teste.

Van Bodegraven (2018) esclarece o quanto a utilização de mensagens humanizadas serão valiosas para a evolução de IoT e interfaces conversacionais:

"A Internet das Coisas (IoT) está crescendo à medida que o mercado e os telefones celulares estão se tornando mais nossos assistentes. Quando entrevistamos nossos entrevistados e perguntados sobre sua opinião sobre Sistemas Operacionais Inteligentes e Inteligência Artificial, a maioria das pessoas se referiu ao filme $\mathrm{Her}$ como uma perspectiva futura.

Esta é uma perspectiva interessante e realista. No entanto, olhando para desenvolvimentos recentes para assistentes inteligentes como Siri, Cortana e Google Home, uma característica essencial está faltando: personalidade.

A personalidade agrega um valor enorme às nossas interações com dispositivos, porque dá um toque humano. As pessoas podem se relacionar mais com dispositivos se tiverem uma personalidade. Olhando para serviços como o Siri, acredito que a personalidade será um ativo mais relevante no futuro do que o número de Gigabytes de armazenamento que vem com um iPhone."

Um outro ponto positivo mencionado pelos participantes, foi a proatividade que o Anticipatory Design pode impor na execução das atividades do Amazon Echo Dot. Podendo ser um diferencial em relação a versão atual existente no mercado. Na versão atual, para que o Amazon Echo Dot funcione de forma efetiva, é preciso que o usuário adicione "Skills". Uma espécie de módulo de funções para que o dispositivo possa efetuar uma atividade específica, tornando-o mais inteligente.
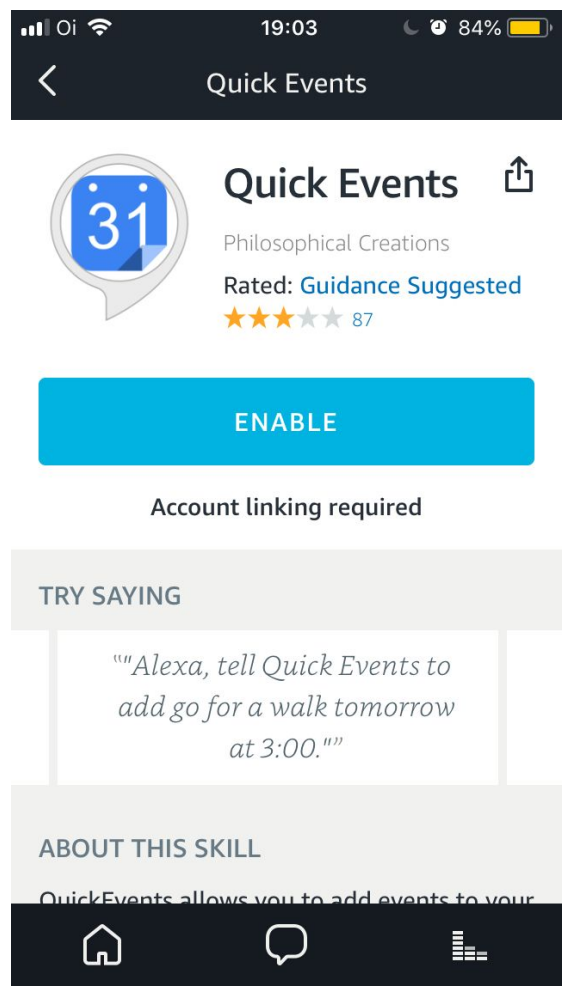

Figura 4 Print da tela do aplicativo Amazon Alexa. Acessado em: 17/06/2018

O exemplo acima, mostra os detalhes de um skill na aplicação de configuração do Amazon Echo Dot. É preciso destacar, que para o usuário utilizar esta função, é preciso mencionar o skills durante a sua execução. No caso do exemplo, o usuário deseja adicionar um evento em sua agenda, através do aplicativo Quick Events. Assim, caso o usuário tenha vários skills adicionados ao dispositivo, $\mathrm{o}$ mesmo terá que lembrar de seu nome para que a função seja executada com êxito. Neste caso, a tendência será o aumento da carga cognitiva e de decisões que o usuário precisará tomar, para utilizar o dispositivo. Proposta completamente inversa aos princípios do Anticipatory Design.

Mesmo sendo um teste em pequena escala, essa dificuldade de uso foi refletida no resultado do SUS. Onde foram encontrados uma certa variação nos resultados da opção em que seria preciso o apoio de suporte técnico para utilizar a versão existente no mercado do Amazon Echo Dot.

Com base nos resultados do teste e com o embasamento teórico apresentado nesta pesquisa. É notável o quanto o Anticipatory Design pode 


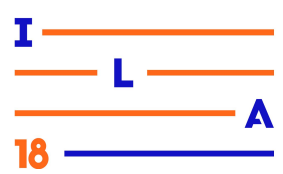

contribuir para a evolução das interfaces conversacionais e assistentes virtuais. Aumentando a interação dos usuários com esta tecnologia.

\section{Conclusões}

A Internet das Coisas pode ser considerada qualquer objeto físico que possui uma camada digital e que está de alguma forma conectado em rede. Estes dispositivos possuem várias formas de interação. Uma delas é a Interface por voz.

Como afirma Rowland (2015), às interfaces de voz são uma maneira poderosa de inserir ou gerar informações razoavelmente complexas, possibilitando aos usuários operá-las enquanto fazem outras coisas.

O desenvolvimento do presente estudo possibilitou uma análise comparativa entre a versão existente no mercado Amazon Echo Dot com uma proposta aplicando o Anticipatory Design. Além disso, também permitiu a execução de um Teste A/B para obter dados mais consistentes sobre quais das versões seria mais eficaz para os usuários.

De um modo geral, os usuários que utilizam assistentes conversacionais, ainda são entusiastas a novas tecnologias e que tem um certo nível de conhecimento em informática. Perfil este, que foi convocado para o teste das duas versões proposta neste artigo.

Ao fazer o Teste A/B e a aplicação do questionário SUS, verificou-se que a Proposta B obteve todos os resultados positivos acima da média de 68 pontos como mostra o Gráfico 1. Permitindo assim, que os objetivos propostos fossem realmente alcançados. Dada à importância do assunto, torna-se necessário o desenvolvimento de melhorias nos métodos de testes comparativos e de usabilidade para interfaces conversacionais. Podendo economizar não só o tempo, mas como tornar este processo mais simples para pesquisas de design de interação.

Nesse sentido, a proposta de aplicação do Anticipatory Design ao Amazon Echo Dot, permite aos usuários realizarem suas atividades de forma rápida e eficiente. Além de diminuir seu esforço cognitivo nas tomadas de decisões. Motivando o uso contínuo do assistente virtual.

A pesquisa não verificou se a ordem das propostas interferiu nos resultados, este aspecto, a execução com um número maior de usuários são propostas para trabalhos futuros.

\section{Referências Bibliográficas}

\section{ASHTON, Kevin. That 'Internet of Things'}

Thing, RFID Jornal, 2009. Disponível em: < http://www.rfidjournal.com/articles/view?4986>

Acesso em: 09 de Maio de 2018

\section{BROOKE, John. SUS - A quick and dirty usability scale. 1986. Disponível em $<$ http://www.usabilitynet.org/trump/documents/Susc hapt.doc $>$ Acesso em: 16 de Junho de 2018}

HOOMANS, Dr. Joel. 35.000 Decisions: The Great Choices of Strategic Leaders, Roberts Wesleyan College, 2015. Disponível em: $<$ https://go.roberts.edu/leadingedge/the-great-choice s-of-strategic-leaders $>$ Acesso em: 25 de Abril de 2018

ISO (International Standard Organization). ISO

9241 Part 210: Human-centred design for interactive systems. ISO 9241-210: 2010 (E).

Genebra: ISO, 2010.

\section{LOPEZ RESEARCH. Uma Introdução à Internet das Coisas (IoT), 2013. Disponível em:}

$<$ https://www.cisco.com/c/dam/global/pt_br/assets/b rand/iot/iot/pdfs/lopez_research_an_introduction_to iot_102413_final_portuguese.pdf $>$ Acesso em: 09 de Maio de 2018

MARCONI, M.; LAKATOS, E. Fundamentos de metodologia científica $5^{\text {a }}$ Edição. Editora Atlas, 2003.

MEIRA, Silvio. Sinais do futuro imediato internet das coisas, Plataformas, mercado em e transformação digital, Much More, 2017. Disponível em: < http://www.muchmore.digital/2017/04/25/sinais-dofuturo-imediato/>. Acesso em: 11 de Maio de 2018

NIELSEN, Jakob. Why You Only Need to Test 


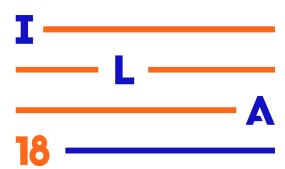

with 5 Users, Nielsen Norman Group, 2000.

Disponível em:

$<$ https://www.nngroup.com/articles/why-you-only-n eed-to-test-with-5-users/> Acesso em: 22 de Maio de 2018

Putting A/B Testing in Its Place, Nielsen Norman Group, 2015. Disponível em: $<$ https://www.nngroup.com/articles/putting-ab-t esting-in-its-place/> Acesso em: 17 de Maio de 2018

NORMAN, Donald A. Design emocional: por que adoramos (ou detestamos) os objetos do dia-a-dia. Rio de Janeiro: Rocco, 2008.

, Donald A. Don Norman on the term "UX", Nielsen Norman Group, 2011. Disponível em:

$<$ https://www.nngroup.com/videos/don-norman-ter m-ux/> Acesso em: 18 de Abril de 2018

PARISER, Eli. The Filter Bubble: How the New
Personalized Web Is Changing What We Read and How We Think. Penguin Books, 2016.

PEARL, Cathy. Designing Voice User Interfaces. O'Reilly, 2017.

ROWLAND, Claire. User Experience Design for the Internet of Things. O'Reilly, 2015.

SAURO, Jeff. Measuring Usability with the System Usability Scale (sus), Measuringu, 2011. Disponível em: $<$ https://measuringu.com/sus/> Acesso em: 06 de Junho de 2018

TEIXEIRA, Fabrício. Desenhando interfaces conversacionais: o desafio de $\mathbf{U X}$, UX Collective BR, 2016. Disponível em: <

https://brasil.uxdesign.cc/desenhando-interfaces-con versacionais-o-desafio-de-ux-5d94cce7e82 $>$ Acesso em: ) 6 de Maio de 2018

VAN BODEGRAVEN, Joël. Introduction to Anticipatory Design 1st Edition, 2018. Disponível em: <www.anticipatorydesign.com>. Acesso em: 11 de Abril de 2018 